\title{
REGIONAL SUESS EFFECT IN THE UPPER SILESIA URBAN AREA
}

\author{
ROMUALD AWSIUK and MIECZYSKAW F PAZDUR
}

\author{
Radiocarbon Laboratory, Silesian Technical University, Krzywoustego 2 \\ PL-44-100 Gliwice, Poland
}

\begin{abstract}
The study of a regional Suess effect is based on three sets of samples of atmospheric $\left.\mathrm{CO}_{2}: 1\right)$ a series of samples collected at the same site in Gliwice from 1980 to 1984,2 ) samples collected simultaneously at different sites within the limits of an urban and industrial region of Upper Silesia, and 3) samples collected simultaneously outside this region along an eastern direction. Results of ${ }^{14} \mathrm{C}$ concentration measurements show systematic decrease of $\Delta^{14} \mathrm{C}$ with the rate close to the corresponding value for clean air. Depletion of ${ }^{14} \mathrm{C}$ concentration was found to be virtually the same in the whole urban area. Analysis of regional synoptic data reveals correlation of individual $\Delta^{14} \mathrm{C}$ values with wind direction, frequency of calm, and vertical stability of the atmosphere.
\end{abstract}

\section{INTRODUCTION}

Since the early studies of Suess (1955) the effect of fossil fuel $\mathrm{CO}_{2}$ admixture on the ${ }^{14} \mathrm{C}$ level in atmospheric $\mathrm{CO}_{2}$ has been investigated by many researchers. Global increase of the $\mathrm{CO}_{2}$ concentration in the atmosphere due to fossil fuel combustion has been described by Keeling (1973). The global Suess effect has been studied intensively in recent years, including both high-precision measurements of ${ }^{14} \mathrm{C}$ in tree rings from the last century ( $c f$ Tans, de Jong \& Mook, 1979) and model predictions of present and future ${ }^{14} \mathrm{C}$ levels in global reservoirs (Bacastow \& Keeling, 1973; Oeschger et al, 1975; Stuiver \& Quay, 1981).

It seems, however, that too little attention has been given to studies of the Suess effect on a local or regional scale. Any separate region with great concentration of industry and/or high population density must be regarded as a surface source of fossil $\mathrm{CO}_{2}$. The atmosphere over such a region should be then treated as a transient local reservoir with diffusive boundaries and highly complicated response function to a given input signal. The modeling of ${ }^{14} \mathrm{C}$ levels in such reservoirs seems to be necessary for further understanding of the carbon cycle in nature. Different mathematical models developed in recent years to describe atmospheric transport and dispersion of gaseous effluents, and discussed by Miller (1984), would be useful in modeling of the local or regional Suess effect. However, in addition to scattered data on ${ }^{14} \mathrm{C}$ levels in some urban areas there are only a few papers dealing with well-defined sites or regions (Vogel \& Uhlitzsch, 1975; Freundlich, 1979; Lewin, Münnich \& Weiss, 1980; Segl et al, 1983; Florkowski \& Kuc, 1979).

The aim of our study is a model description of the regional Suess effect in the Upper Silesia urban area. We present here the results of the first stage of this study, which include evaluation of the magnitude of the fossil fuel effect and its time and territorial variability, estimation of the characteristic dimension of the reservoir, and finally, the correlations with some regional synoptic data. 


\section{SAMPLING AREA}

The area of our study coincides with the Silesian Upland and corresponds to administrative boundaries of the Katowice district. Mean population density is equal to 525 inhabitants per $\mathrm{km}^{2}$. Two regions of extreme high population density are in the Katowice district, ie, the Upper Silesia area and the vicinity of Rybnik (with ca 1300 and 900 inhabitants $/ \mathrm{km}^{2}$, respectively). This is also the region of greatest concentration of heavy industry in Poland. Total consumption of pit coal could be estimated to ca $12 \mathrm{kt}$ per $\mathrm{km}^{2}$ per year. Most samples were collected in Gliwice, the western part of this area, others in areas approximately on a west-east line between Gliwice and Sosnowiec. Two sampling sites (Racibórz and Rybnik) are ca 40 and $30 \mathrm{~km} \mathrm{SW}$ of Gliwice, respectively.

\section{LABORATORY METHODS}

Samples were collected as in the study of Nydal, Lövseth and Gulliksen (1979) by static absorption of $\mathrm{CO}_{2}$ in $\mathrm{NaOH}$ solution. Ca 31 of $1 / 2 \mathrm{~N} \mathrm{NaOH}$ were placed in an open dish $\left(\mathrm{ca} \mathrm{m}^{2}\right)$ and exposed to the atmospheric air for one week. In an industrial area dishes were exposed on roofs of the buildings ca $10 \mathrm{~m}$ above ground level; in rural areas samples were collected at farms at least $100 \mathrm{~m}$ away from roads ( $c f$ Freundlich, 1979). Only distilled water was used to avoid contamination. After exposure, the samples were transferred to plastic bottles and sent to the laboratory where a hot solution of $\mathrm{CaCl}_{2}$ was added in excess and $\mathrm{CaCO}_{3}$ was precipitated. $\mathrm{CO}_{2}$ was produced from $\mathrm{CaCO}_{3}$ in the next step by adding $8 \% \mathrm{HCl}$ in vacuum.

\section{RESULTS AND DISCUSSION}

The magnitude of the regional Suess effect is expressed by the parameter ${ }^{14} \mathrm{~S}$, defined as

$$
{ }^{14} \mathrm{~S}=\frac{\Delta^{14} \mathrm{C}-\Delta^{14} \mathrm{C}_{\mathrm{o}}}{\Delta^{14} \mathrm{C}_{\mathrm{o}}+1000} 100 \%,
$$

where $\Delta^{14} \mathrm{C}$ is the measured concentration of ${ }^{14} \mathrm{C}$ in a sample, according to Stuiver and Polach (1977), and $\Delta^{14} \mathrm{C}_{\mathrm{o}}$ is the corresponding ${ }^{14} \mathrm{C}$ concentration in "clean air." Values of $\Delta^{14} C_{0}$ were estimated from the data of Nydal and Lövseth (1983) by least squares fitting of exponential curve

$$
\Delta^{14} \mathrm{C}_{\mathrm{o}}=372 \exp (-0.0582 \mathrm{t}),
$$

where t-time elapsed since 1976/01/01. This time dependence is very close to that obtained by Segl et al (1983) from linear fitting of their own data.

\section{Magnitude of the Suess Effect}

The values of $\Delta^{14} \mathrm{C}$ of $\mathrm{CO}_{2}$ samples collected in an urban area since February 1980 to April 1984 are shown in Figure 1. Only a few points lie above the "clean air" level, marked by a solid line (eq 2). The first series of 8 samples collected in 1980 gave similar values of $\Delta^{14} \mathrm{C}$ and ${ }^{14} \mathrm{~S}$, with a mean value, ${ }^{14} \overline{\mathrm{S}}=-5.17 \pm 0.41 \%$, coinciding with the value ${ }^{14} \mathrm{~S}=-5.84 \pm 1.0 \%$, obtained on a $\mathrm{CO}_{2}$ sample collected in Gliwice in January 1974. To check 


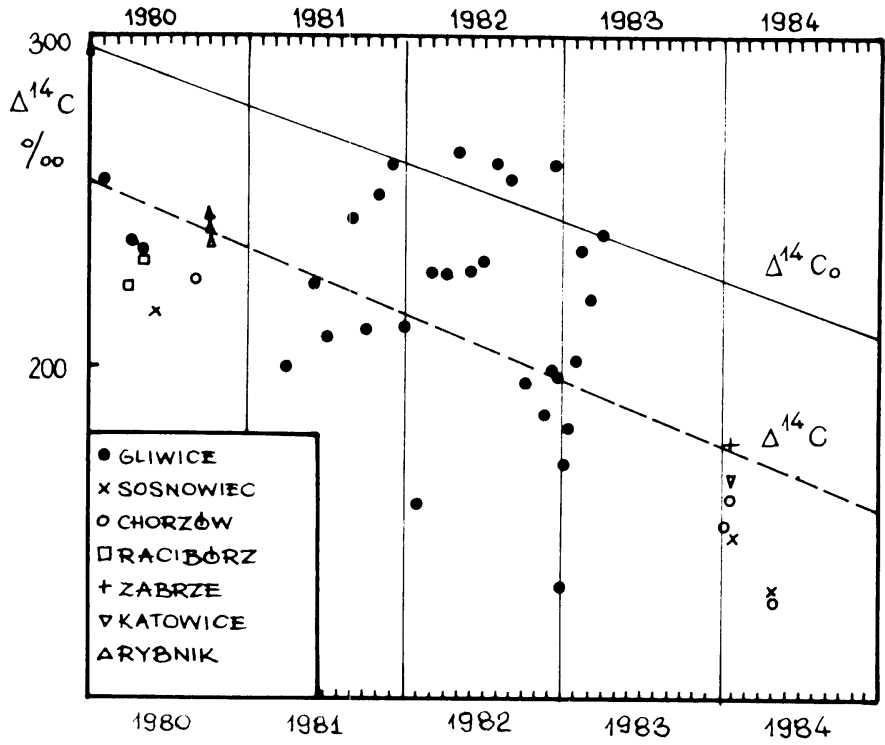

Fig 1. Results of ${ }^{14} \mathrm{C}$ measurements in samples of atmospheric $\mathrm{CO}_{2}$ from an Upper Silesia urban area. All data points follow approximately the same errors of 6 to $8 \%(1 \sigma)$.

the assumption of a constant level of ${ }^{14} \mathrm{C}$ over the whole urban area, a series of $\mathrm{CO}_{2}$ samples was collected at the same time from 5 sites along a west-east line. The obtained mean value ${ }^{14} \overline{\mathrm{S}}=-5.54 \pm 0.40 \%$ is close to previous values.

\section{Time Variations}

The values of $\Delta^{14} \mathrm{C}$ in Figure 1 do not show pronounced summer-winter variations, similar to those found by Lewin, Münnich and Weiss (1980). Despite this, the lowest values occur in winter months, and 3 out of 4 points exceeding the "clean air" level are found in samples collected in spring and summer. Such a different pattern of ${ }^{14} \mathrm{C}$ variations in our region as compared to the Heidelberg data is caused by the two factors: 1) a significant amount of fossil $\mathrm{CO}_{2}$ produced by heavy industry, which is not subject to seasonal variability, and 2) different topographic features of both regions.

Fitting a straight line to the data shown in Figure 1 gives smoothed time dependence

$$
\Delta^{14} \mathrm{C}=254-19.6 \mathrm{t}
$$

where t denotes time in years from the beginning of 1980. This dependence is shown in Figure 1 as a dashed line, together with the solid line denoting the "clean air" level, obtained from extrapolation of Eq 2. In linear approximation, we obtain

$$
{ }^{14} \mathrm{C}_{\mathrm{o}}=295-17.2 \mathrm{t} .
$$


Using Eqs 3 and 4, the smoothed time dependence of the Suess effect over the Upper Silesia urban area takes the form:

$$
{ }^{14} \mathrm{~S}=-3.16-0.242 \mathrm{t} .
$$

\section{Territorial Range of the Suess Effect}

Two series of atmospheric $\mathrm{CO}_{2}$ samples were collected along a westeast line beyond the boundaries of Upper Silesia. The first series collected 1981/06/06-15 include samples from Gliwice, Jedrzejów $(120 \mathrm{~km} \mathrm{E})$, Iwaniska $(240 \mathrm{~km} \mathrm{E})$, Janów Lubelski $(390 \mathrm{~km} \mathrm{E})$, and Hrubieszów $(470 \mathrm{~km} \mathrm{E}$ of Gliwice). The second series, collected 1984/04/19-25, includes samples from sites between Gliwice and Iwaniska. The obtained values of ${ }^{14} \mathrm{~S}$ are shown in Figure 2. Unexpectedly low values of ${ }^{14} \mathrm{~S}$ in both samples from Iwaniska could possibly be explained by admixture of fossil fuel $\mathrm{CO}_{2}$ from local sources in Połaniec and Ostrowiec. After rejecting three outlying data points (in parentheses), we obtained strictly linear dependence of $\ln \left(-{ }^{14} \mathrm{~S}\right)$ upon distance, leading to:

$$
{ }^{14} \mathrm{~S}=-5.0 \exp (-0.0072 \mathrm{~d})
$$

where d-distance (in $\mathrm{km}$ ) of Gliwice. The mean relaxation length, $\mathrm{l}_{\mathrm{r}}$, of the regional Suess effect is then estimated to $l_{r}=140 \mathrm{~km}$, though due to scarce data, this figure indicates the order of magnitude only.

\section{Correlations with Some Meteorologic Parameters}

Due to the very rapid mixing rate of the atmosphere, the studies of local or regional Suess effect based on ${ }^{14} \mathrm{C}$ measurements in atmospheric $\mathrm{CO}_{2}$ must account for the physical state of the atmosphere during the period of sample collection. Such effects were observed by Nydal and Lövseth (1983) in their ${ }^{14} \mathrm{C}$ measurements from Santiago de Compostella. In our analysis, we used 31 values of $\Delta^{14} \mathrm{C}$ in samples collected in Gliwice from 1980-1983. First, the large scatter of ${ }^{14} \mathrm{~S}$ values was observed in samples collected during periods of dominating winds from the southwest. Samples were then excluded from further analysis that were collected when the frequency of winds from the southwest was $>40 \%$ and the mean wind velocity from this direction was $>4 \mathrm{~m} / \mathrm{s}$. The resulting data set, consisting of

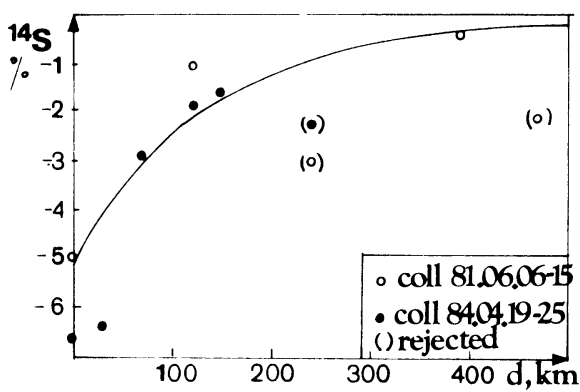

Fig 2. Exponential decrease of the Suess effect beyond an Upper Silesia urban area 


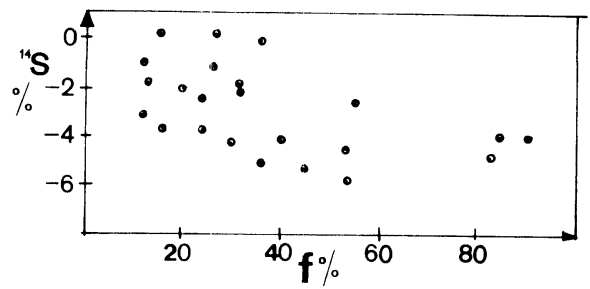

Fig 3. Dependence of the Suess effect upon the mean wind frequency from NE-SE and calm. Correlation coefficient $r=0.487$, critical value $r_{\alpha}=0.34$ for $\alpha=0.1$.

23 results, was then analyzed to find dependence of ${ }^{14} \mathrm{~S}$ upon the following parameters: 1) mean wind velocity, $\bar{v}$; 2) joint frequency of winds from NE$\mathrm{SE}$ and a calm, f; 3) vertical stability of the atmosphere, $s$.

1) No significant dependence was found between ${ }^{14} S$ and $\bar{v}$. The correlation coefficient $r\left({ }^{14} \mathrm{~S}, \overline{\mathrm{v}}\right)=0.275$ is less than the critical value at the significance level $\alpha=0.1, \mathrm{r}_{\alpha}=0.34$.

2) This dependence is shown in Figure 3. A distinct increase of ${ }^{14} \mathrm{~S}$ occurs with the increasing parameter $\mathrm{f}$. The correlation coefficient $\mathrm{r}\left({ }^{14} \mathrm{~S}\right.$, f) $>\mathrm{r}_{\alpha}=0.34$ for $\alpha=0.1$.

3) The parameter s, used to describe the vertical stability of the atmosphere, is defined as the ratio of the number of days with unstable equilibrium of the atmosphere to the total number of days of sample collection. This dependence is shown in Figure 4. Two groups of points clearly show quite different behavior. Group A, corresponding to a highly stable atmosphere $(s \approx 0.1)$ shows a large scatter of ${ }^{14} S$ values, while group $B$ reveals significant dependence of ${ }^{14} \mathrm{~S}$ upon $\mathrm{s}$, with correlation coefficient $r\left({ }^{14} \mathrm{~S}, \mathrm{~s}\right)=$ $0.687>\mathrm{r}_{\alpha}=0.55$ for $\alpha=0.1$.

\section{CONCLUSIONS}

The experimental data presented in this paper and the results of some calculations lead to the conclusions that

1) a virtually constant ${ }^{14} \mathrm{C}$ level in the whole urban area of Upper Silesia confirms our assumption that the study area can be treated as the uni-

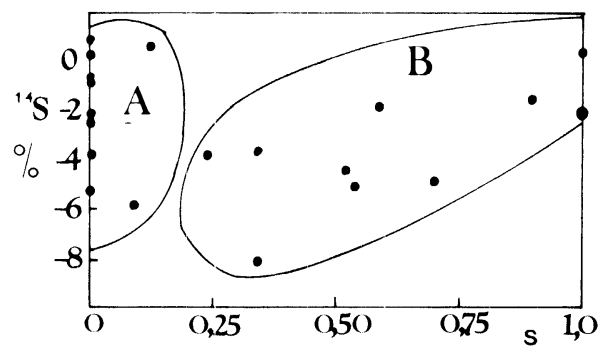

Fig 4 . The effect of the vertical stability of the atmosphere on the measured ${ }^{14} \mathrm{~S}$ values in atmospheric $\mathrm{CO}_{2}$ samples 
form surface source of fossil $\mathrm{CO}_{2}$ with a characteristic dimension of ca $10 \mathrm{~km}^{2}$;

2) more accurate determination of the territorial range of the regional Suess effect should be based on series of ${ }^{14} \mathrm{C}$ measurements in plant samples;

3) group A of results in Figure 4 shows the kind of memory effect of the atmosphere over the studied area, $i e$, in periods of highly stable atmosphere $(\mathrm{s} \approx 0.1)$ the measured ${ }^{14} \mathrm{C}$ level reflects the previous-time level. Group $\mathrm{B}$ in Figure 4 indicates that the mean residence time of the local fossil fuel $\mathrm{CO}_{2}$ is equal to ca 3-4 days.

\section{ACKNOWLEDGMENTS}

Thanks are due Stanisław Hałas, Institute of Physics, Maria Curie Skłodowska University, Lublin, for his help in mass spectrometric measurements of the $\mathrm{CO}_{2}$ samples.

\section{REFERENCES}

Bacastow, R B and Keeling, C D, 1973, Atmospheric carbon dioxide and radiocarbon in the natural carbon cycle, in Woodwell, GM and Pecan, E V, eds, Carbon and the biosphere, Brookhaven symposium in biol, 24th, Proc: Upton, New York, p 86-135.

Florkowski, T and Kuc, T, 1979, Carbon isotopes and sulphur content as indicators of atmospheric pollution from burning fossil fuels: Environment Internatl, v 2, p 431-435.

Freundlich, J C, 1979, Fossil fuel exhaust-gas admixture with the atmosphere, in Berger, R and Suess, $\mathrm{H}$ E, eds, Radiocarbon dating, Internatl ${ }^{14} \mathrm{C}$ conf, 9 th, Proc: Berkeley/Los Angeles, Univ California Press, p 388-393.

Keeling, C D, 1973, Industrial production of carbon dioxide from fossil fuel and limestone: Tellus, v 25, p $174-197$.

Lewin, I, Münnich, K O and Weiss, W, 1980, The effect of anthropogenic $\mathrm{CO}_{2}$ and ${ }^{14} \mathrm{C}$ sources on the distribution of ${ }^{14} \mathrm{C}$ in the atmosphere, in Stuiver, $\mathrm{M}$ and Kra, RS, eds, Internatl ${ }^{14} \mathrm{C}$ conf, 10th, Proc: Radiocarbon, v 22, no. 2, p 379-391.

Miller, C W, 1984, Atmospheric dispersion and deposition, in Miller, C W, ed, Models and parameters for environmental radiological assessments: US Dept Energy, DOE/TIC 11468 , p $11-20$.

Nydal, R and Lövseth, K, 1983, Tracing bomb ${ }^{14} \mathrm{C}$ in the atmosphere 1962-1980: Jour Geophys Research, v 88, p $362 \mathrm{l}-3642$.

Nydal, R, Lövseth, K and Gulliksen, S, 1979, A survey of radiocarbon variation in nature since the Test Ban Treaty, in Berger, $\mathrm{R}$ and Suess, $\mathrm{HE}$, eds, Radiocarbon dating, Internatl ${ }^{14} \mathrm{C}$ conf, 9th, Proc: Berkeley/Los Angeles, Univ California Press, p 313-323.

Oeschger, H, Siegenthaler, U, Schotterer, U and Gugelman, A, 1975, A box diffusion model to study the carbon dioxide exchange in nature: Tellus, v 27, p 168-192.

Segl, M, Lewin, I, Schoch-Fischer, H, Münnich, M, Kromer, B, Tschiersch, J and Münnich, $\mathrm{K}$ O, 1983, Anthropogenic ${ }^{14} \mathrm{C}$ variations, in Stuiver, $\mathrm{M}$ and $\mathrm{Kra}, \mathrm{R} \mathrm{S}$, eds, Internatl ${ }^{14} \mathrm{C}$ conf, 11 th, Proc: Radiocarbon, v 25, no. 2, p 583-592.

Stuiver, M and Polach, H A, 1977, Discussion: Reporting of ${ }^{14} \mathrm{C}$ data: Radiocarbon, v 19, p 355-363.

Stuiver, M and Quay, P D, 1981, Atmospheric ${ }^{14} \mathrm{C}$ changes resulting from fossil fuel $\mathrm{CO}_{2}$ release and cosmic ray flux variability: Earth Planetary Sci Letters, v 53, p 349-362.

Suess, H E, 1955, Radiocarbon concentration in modern wood: Science, v 122, p 415-417.

Tans, P P, de Jong, A F M and Mook, W G, 1979, Natural atmospheric ${ }^{14} \mathrm{C}$ variations and the Suess effect: Nature, v 280, p 826-827.

Vogel, J C and Uhlitzsch, I, 1975, Carbon-14 as an indicator of $\mathrm{CO}_{2}$ pollution in cities, in Isotope ratios as pollutant source and behavior indicators: Vienna, IAEA, p 143-152. 